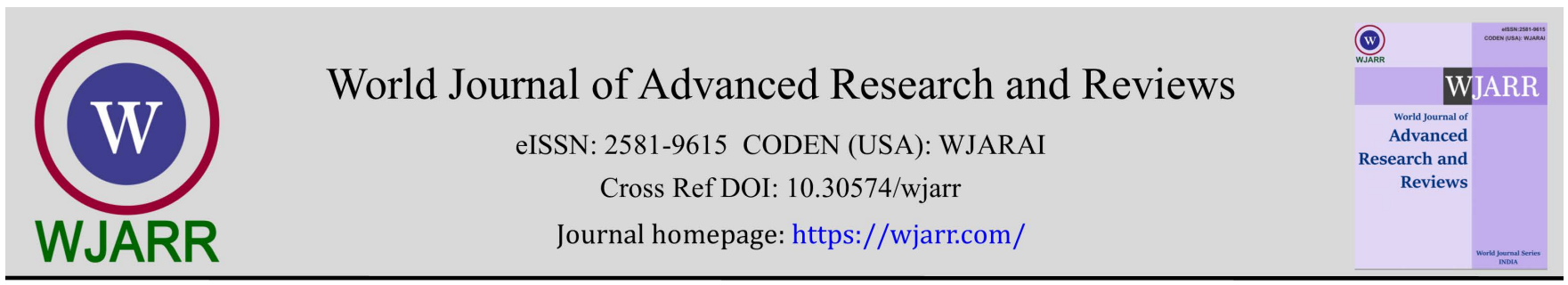

(RESEARCH ARTiClE)

\title{
Harvester wheel energy (type 4)
}

\author{
Mohammed Alaa Alwafaie* and Béla Kovács \\ István Sályi Doctoral School of Mechanical Engineering Sciences, University of Miskolc, Hungary.
}

World Journal of Advanced Research and Reviews, 2022, 13(02), 304-308

Publication history: Received on 07 January 2022; revised on 10 February 2022; accepted on 12 February 2022

Article DOI: https://doi.org/10.30574/wjarr.2022.13.2.0147

\begin{abstract}
Since the advent of modern civilization, humans have always been depended upon the fossil fuels as the source of energy for their daily requirements. With the exponential growth in the population, the dependence on these conventional sources for the daily energy requirements has led to the depletion of the same and adverse ill-effects on the environment. To lessen the burden and if possible, minimize to zero, energy harvesting has become the need of the hour and the development of the different energy harvesting technologies has been the prime area of research. Of them, piezoelectric materials have gained the popularity in this niche of energy harvesting solutions and have resulted in promising possibilities of efficient tapping of waste energy for future use. In this paper, a technique of application of piezoelectric material for harnessing energy i.e., along the circumference of the inner lining of the tire and rough calculations has been made to project the probable energy tapped and its usage. The current work describes a sample arrangement of crystal and various new arrangements based on maximum power output can be made.
\end{abstract}

Keywords: Energy Harvesting; Piezoelectric Effect; Piezoelectric crystals; Capacitor

\section{Introduction}

With the increase in the concern for the alarming depletion of fossil fuel reserves and its adverse effects on the surrounding environment, the alternative non-conventional sources of energy have gained popularity in the society. Starting from the well-known solar cells to the wind turbines, hydroelectric power generation, biodiesel and biogas plants have already been successfully proven and implemented for the same. For power supply needs of the portable gadgets the human use, new ways have been found out to cater the need. Piezoelectric materials and the effect itself have played a major role in solving such problems. Energy harvested from the vibrations is one of the easiest and omniusable techniques. These vibrations can be from human motion, vehicular motion, machines and any other surface under vibrations. The conversion of mechanical energy into electrical energy can be done by the use of piezoelectric materials. Some of the natural piezoelectric materials already in use is quartz. Some artificial piezoelectric materials like BaTiO3, Lead Zirconium Titanate etc. find their applications in modern electronic circuits.

Vehicle tires are subjected to normal and shear loads under static and dynamic conditions. The load can be used as a source of mechanical stress for the piezoelectric crystals. The piezoelectric crystals can thus be aligned along the inner lining of the tire where the air pressure does the work. In this paper, different applications of piezoelectric energy harvesting are being illustrated and an attempt has been made to conceptualize a new way of application of the same and certain calculations has been made to visualize the probable energy output from the system.

\footnotetext{
${ }^{*}$ Corresponding author: Mohammed Alaa Alwafaie

István Sályi Doctoral School of Mechanical Engineering Sciences, University of Miskolc, Hungary. 


\subsection{Piezoelectric Materials}

Piezoelectric Materials are the smart materials which convert mechanical stress or strain into electrical potential and vice versa i.e., application of electrical potential to the material yields to mechanical displacement. While the former is known as direct piezoelectric effect, the latter is reverse piezoelectric effect. The piezoelectric material in the piezoelectric system has different modes of operation. The modes are characterized by piezoelectric strain constant dij, mechanical strain to electrical voltage. The subscript „i" denotes the direction of electrical voltage output and ,j" denotes the direction of application of mechanical stress or deformation. There are predominately two constants d33 and d31 with the poling direction being the 3 -axis.

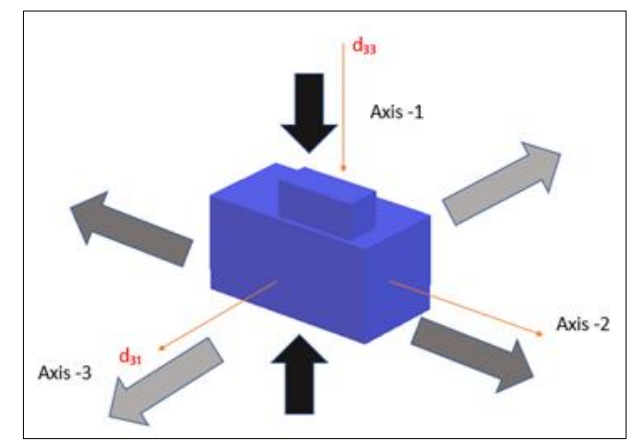

Figure 1 System for reference axis generation by piezoelectric materials

Piezoelectric materials include quartz, BaTiO3, Lead Zirconium Titanate (PZTs) etc. Out of these quartz gives highest electrical output voltage w.r.t the mechanical stress applied but it is economically not feasible due to its high cost. The next is PZT which are readily available at low cost and gives impressible results. The following graphs [5] give a clear picture of different PZT materials under various working conditions in terms of temperatures.

\section{Procedures of piezoelectric}

The availability and cost of the PZT-5J is more feasible than the other PZT materials. Therefore, PZT-5J material was chosen. The module chosen is of thickness $2 \mathrm{~mm}$. The PZT-5J modules are placed in all along the inner circumference of the tire. The load experienced by the tire is profound in the contact patch area where the modules also experience the mechanical stress. The electrical voltage produced in the modules is fed to the capacitor bank for storage. The flowchart of the working of the system is described in the figure 2.

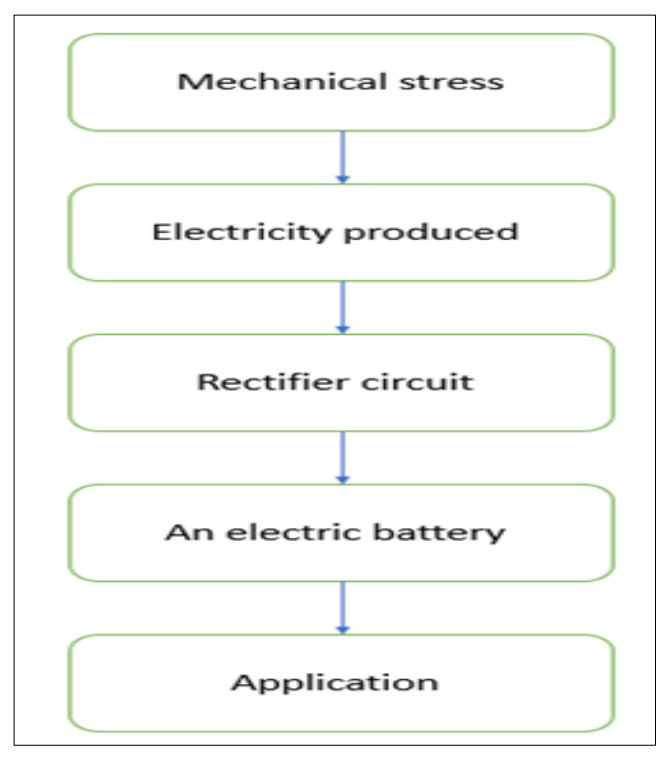

Figure 2 Flowchart of the project 


\section{The calculation of HWE}

Taking a look at the following table \& Figur3 one must first become familiar with the type of wheel which Goodyear manufactures and identify its technical characteristics according to its specifications.

\begin{tabular}{|l|l|}
\hline Diameter & $25 "$ \\
\hline Width & $7 .{ }^{\prime \prime}$ \\
\hline Rim Range & $5.5-7^{~ "}$ \\
\hline Max Load & $1356 \mathrm{lbs}$ \\
\hline Max PSI & $51 \mathrm{psi}$ \\
\hline Speed & $149 \mathrm{mph}$ \\
\hline REVS/Mile & 831 \\
\hline
\end{tabular}

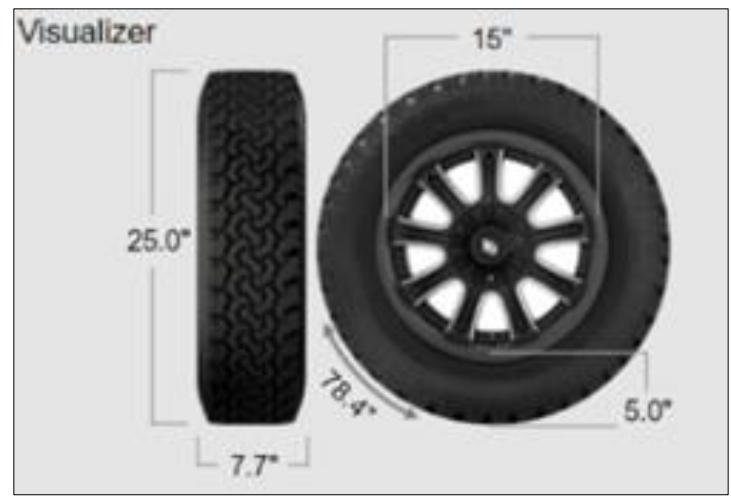

Figure 3 Characteristic of Goodyear wheal 196/65R15"

Before calculation it is better to know some of work environment data for the system as follows:

Pizo electric charge constant: $d_{33}=485 \times 10^{-12} \mathrm{C} / \mathrm{m}^{2}$.

Pizo voltage coefficient: $g_{33}=21.3 \times 10^{-3} \mathrm{Vm} / \mathrm{N}$.

The mechanical stress gives as:

$\sigma=$ force on each module / area of application of load.

$=\mathrm{F} / \mathrm{A}$

$=$ load of tire $/ \pi \cdot R^{2}$

$=615 \times 9.18 \times 4 / 3.14(0.3175)^{2}$

$=71344.53 \mathrm{~N} / \mathrm{m}^{2}$

Open Circuit Voltage $(\mathrm{OCV})=\mathrm{g}_{33} \times \sigma \times \tau$

$\tau$ : thickness of the model $=2.10^{-3} \mathrm{~m}$

$\mathrm{OCV}=21.3 \times 10^{-3} \times 71344.53 \times 2.10^{-3}$ 
$=3.04$ volt

Charge Density $(C D)=d_{33} \times \sigma$

$=0.035 \mathrm{mC} / \mathrm{m}^{2}$

Therefore, the density of each model on the area contacts with ground equal. so that it is better to know the area of contact and it gives as = load of the wheel / Air pressure in wheel.

$A=615 \times 9.18 / 6894.76 \times 51 \times 10^{-6}$

$=0.01716 \mathrm{~m}^{2}$

So, density of each model $=\mathrm{CD} \cdot \pi \cdot \mathrm{R}^{2}$

$=0.035 \times 3.14 \times(0.01716)^{2}$

$=0.032 \mu \mathrm{A}$

Power output $\mathrm{P}=\mathrm{I} . \mathrm{V}$

$=0.032 \times 3.04 \approx 0.0973 \approx 0.1 \mu \mathrm{W}$ for $(1 \mathrm{sec})$

Assuming the vehicle is running at a speed of $40 \mathrm{kmph}$ i.e., $11.11 \mathrm{~m} / \mathrm{s}$, then, the number of wheel rotations per second is:

Velocity / $2 \pi R=5.57$ rotation/sec.

Therefore, power output per wheel per second $=5.6 \times 0.1$

$=0.56 \mu \mathrm{W}$

\section{Results}

It can be seen that the amount of energy that can be stored from a sec of driving with the present design of the system is enough for catering the power supply needs of various electronic circuits of the vehicle. Proper designing and experiments can lead to better results. Although the efficiency of such systems is around 30-40\%, use of better quality PZT -5J materials can yield better results. The amount of energy that can be produced is enough to charge mobile phones or can be held as power store for the LED headlights which consume very less power as compared to the conventional headlights.

\section{Conclusion}

With the increase of popularity of non-conventional energy sources among the researchers all over the world, the possibilities of energy harvesting by the use of piezoelectric materials paves its way towards major green technology designs. Experiments and prototyping can lead to better collation of theoretical results and practical world outcomes. Great temporal and financial investments are required for the research of such promising outcomes of the piezoelectric energy harvesting concepts. Better materials selection, system design, efficient storage system and piezoelectric module design will guide this new concept of technology to be the next alternative source of energy in the near future.

\section{Compliance with ethical standards}

\section{Acknowledgments}

I would like to express my special thanks of gratitude and appreciation to my Professors in Miskolc university specially Prof. Béla Kovács for helping me with this research, in addition we would like to thank all the parties who helped in writing of this article which includes Harvester wheel energy (type 4). 


\section{Disclosure of conflict of interest}

The authors agree no conflict of interest.

\section{References}

[1] Matthew W. Hooker, "Properties of PZT-based piezoelectric Ceramics between -1500C and 2500C" in NASA/CR1998-208708.

[2] Xiaofeng Li, Vladimir Strezov. Modelling Piezoelectric energy harvesting in an educational building" in Energy Conversion and Management. 2014; 85: 435-442.

[3] ItikaTandon, Alok Kumar. Unique step towards generation of electricity via new methodology in International Journal of Advanced Research in Computer and Communication Engineering (IJARCCE). October 2014; 3(10).

[4] Manla G, White NM, Tudor J. Harvesting energy from vehicle wheels. Solid- State Sensors, Actuators and Microsystems. Transducers. 2009.

[5] Tire Size Visualizer, tire size calculator web site, shown in 01/24/2022, taken from (https://tiresize.com). 